\title{
Hyponatremia as a Specific Marker of Perforation in Infants with Necrotizing Enterocolitis
}

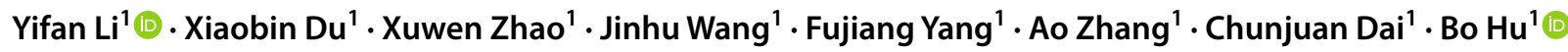

Received: 17 November 2021 / Accepted: 28 January 2022 / Published online: 5 March 2022

(c) Dr. K C Chaudhuri Foundation 2022

To the Editor: Necrotizing enterocolitis (NEC) is a frequent digestive system disease in newborns. When intestinal perforation and pneumoperitoneum develop, surgical therapy should be administered as soon as possible.

We did a retrospective analysis of 396 NEC patients admitted to the Neonatal Surgery Department of Tianjin Children's Hospital between October 2017 and September 2021. During surgery, the presence of intestinal perforation was established. The white blood cell (WBC) count, $\mathrm{C}$-reactive protein (CRP), procalcitonin (PCT), prealbumin, and serum sodium were all measured in the lab. Logistic regression was used to identify independent predictors of perforation among the variables with significant differences.

Perforation occurred in 16 (4.04\%) of the 396 NEC patients studied. The gestational age was lower in the perforation group $(p=0.007)$. Furthermore, there were statistical differences between the two groups in WBC count, CRP, PCT, prealbumin, and serum sodium. Thirteen of the 16 patients with perforation had blood sodium levels of less than $135 \mathrm{mmol} / \mathrm{L}$.

There are currently no laboratory indications that can differentiate perforation in children with NEC. According to logistic regression analysis, hyponatremia $(\mathrm{OR}=9.64,95 \%$ $\mathrm{CI}=2.84-47.63, p=0.002), \mathrm{CRP}>8 \mathrm{mg} / \mathrm{L}(\mathrm{OR}=9.49$, $95 \% \mathrm{CI}=1.52-59.33, p=0.0016)$, and PCT $>10 \mathrm{ng} / \mathrm{mL}$ $(\mathrm{OR}=8.94,95 \% \mathrm{CI}=1.89-42.3, p=0.006)$ were revealed to have promise as laboratory indicators for predicting perforation.

Adam Heymowski et al. [1] and Giannis et al. [2] discovered that hyponatremia was strongly linked to complex appendicitis perforation. Although hyponatremia has a substantial link with perforation, there is currently a lack of relevant basic studies. Furthermore, CRP and PCT have been shown in various trials to be predictors of severe NEC $[3,4]$. As a result, hyponatremia is a specific marker of perforation in infants with necrotizing enterocolitis. However, multicenter data and prospective studies are required to corroborate our findings.

Funding This research was funded by Tianjin Children's Hospital Development Fund project (No:Y2020006).

\section{Declarations}

Conflict of Interest None.

\section{References}

1. Heymowski A, Boström L, Dahlberg M. Plasma sodium and age are important markers of risk of perforation in acute appendicitis. J Gastrointest Surg. 2021;25:287-9.

2. Giannis D, Matenoglou E, Moris D. Hyponatremia as a marker of complicated appendicitis: a systematic review. Surgeon. 2020;18:295-304.

3. Duci M, Fascetti-Leon F, Erculiani M, et al. Neonatal independent predictors of severe NEC. Pediatr Surg Int. 2018;34:663-9.

4. Yu L, Tian J, Zhao X, et al. Bowel perforation in premature infants with necrotizing enterocolitis: risk factors and outcomes. Gastroenterol Res Pract. 2016;2016:6134187.

Publisher's Note Springer Nature remains neutral with regard to jurisdictional claims in published maps and institutional affiliations.

Yifan Li and Xiaobin Du contributed equally to the manuscript.

$\mathrm{Bo} \mathrm{Hu}$

surgeonhubo@163.com

1 Neonatal Surgery Department, Tianjin Children's Hospital, Tianjin 300074, China 